\title{
ERRATUM
}

\section{Growing towards obesity and metabolic syndrome: from a perspective of systems physiology and nutrition}

International Journal of Obesity (2010) 34, 1230; doi:10.1038/ijo.2010.89

Department of Medicine-Physiology, University of Fribourg, Switzerland

30 September 2005

3rd Fribourg Obesity Research Conference (FORC)-2005

Organized in association with the

Swiss Cardiovascular Research Training Network

Swiss Association for Study of Obesity

Swiss Society for Nutrition Research

Swiss Physiological Society

Guest Editor: AG Dulloo

Correction: Since the publication of IJO (2006) Volume 30 Supplement 4, the editors have identified that disclosure statements for authors who contributed to the supplement were omitted. Through this omission, the supplement did not comply with the National Library of Medicine's policy for conflict of interest disclosure for journal supplements.

We are therefore listing the disclosure statements here below.

Propellers of growth trajectories to obesity and the metabolic syndrome

AG Dulloo, V Antic, Z Yang and J-P Montani

Int J Obes 30: S1-S3; doi:10.1038/sj.ijo.0803512

Conflict of interest

The authors declare no conflict of interest.

Obesity during growth in Switzerland: role of early sociocultural factors favouring sedentary activities PM Suter and N Ruckstuhl

Int J Obes 30: S4-S10; doi:10.1038/sj.ijo.0803513

Conflict of interest

The authors declare no conflict of interest.

Early adiposity rebound: causes and consequences for obesity in children and adults

MF Rolland-Cachera, M Deheeger, M Maillot and F Bellisle Int J Obes 30: S11-S17; doi:10.1038/sj.ijo.0803514

Conflict of interest

The authors declare no conflict of interest.
Early growth, and coronary heart disease and type 2 diabetes: experiences from the Helsinki Birth Cohort Studies JG Eriksson

Int J Obes 30: S18-S22; doi:10.1038/sj.ijo.0803515

Conflict of interest

The authors declare no conflict of interest.

The thrifty 'catch-up fat' phenotype: its impact on insulin sensitivity during growth trajectories to obesity and metabolic syndrome

AG Dulloo, J Jacquet, J Seydoux and J-P Montani

Int J Obes 30: S23-S35; doi:10.1038/sj.ijo.0803516

Conflict of interest

The authors declare no conflict of interest.

Adiposity in children born small for gestational age

L Tappy

Int J Obes 30: S36-S40; doi:10.1038/sj.ijo.0803517

Conflict of interest

The authors declare no conflict of interest.

Developmental origins of obesity: a sympathoadrenal perspective

JB Young

Int J Obes 30: S41-S49; doi:10.1038/sj.ijo.0803518

Conflict of interest

The authors declare no conflict of interest.

Dietary fat and fat types as early determinants of childhood obesity: a reappraisal

K Macé, Y Shahkhalili, O Aprikian and S Stan

Int J Obes 30: S50-S57; doi:10.1038/sj.ijo.0803519

Conflict of interest

The authors declare no conflict of interest.

Weight cycling during growth and beyond as a risk factor for later cardiovascular diseases: the 'repeated overshoot' theory J-P Montani, AK Viecelli, A Prévot and AG Dulloo Int J Obes 30: S58-S66; doi:10.1038/sj.ijo.0803520

Conflict of interest

The authors declare no conflict of interest. 